\title{
Manufacture 4.0 with LabVIEW and Arduino Mega for distributed cooling control of the DeMag 250 Ton machine injection mold
}

\section{Manufactura 4.0 con LabVIEW y Arduino Mega para el control de enfriamiento distribuido del molde de inyección de la maquina DeMag 250 Ton.}

\author{
MORENO, José Miguel†*, MORALES, Victor Alfonso, RUIZ, Cesar Alejandro and PÉREZ, \\ Guillermo Rubén
}

Universidad Politécnica de Juventino Rosas. Plastics Engineering Department. Hidalgo 102, Community of Valencia Santa Cruz de Juventino Rosas, Guanajuato, Mexico.

ID $1^{\text {st }}$ Author: José Miguel, Moreno-Reyes / ORC ID: 0000-0003-1913-1230, CVU CONACYT ID: 209863

ID $1^{\text {st }}$ Coauthor: Victor Alfonso, Morales-Nieto / CVU CONACYT ID: 373002

ID $2^{\text {nd }}$ Coautor: Cesar Alejandro, Ruiz

ID $3^{\text {rd }}$ Coauthor: Guillermo Rubén, Pérez.

DOI: $10.35429 / J R D .2020 .18 .6 .5 .10$

Received: July 29, 2020; Accepted: December 19, 2020

\begin{abstract}
Nowdays the injection plastics processes at insdustrial level have had a great development in the bajio region with the arrival of new enterprise suppliers of the automotive industry that work particuary de injection molding. The plastics injection molding is a semicontinuous process that consists of inject a polymer in the molten state into a mold closed under pressure, throught a small hole called gate, in the mole the material is solidifies, the piece or final part is obtained when the mold is opened and remove the piece molding from the cavity [1]. To monitor and control the temperature changes in the plastics injection cicles permite reduce errors and costs in the process. In this project we propose to apply manufacture 4.0 using the Arduino Mega microcontroller and LabVIEW to monitor part of the process of the injection molding of the DeMag 250 Ton Machine, specifically the coolding system adapting to control the injection molde temperature. The preliminare results show that is apropiate to use the LabVIEW an Arduino Mega combination to generation of innovation project applied to the plastic industry.
\end{abstract}

Injection molding, manufacture 4.0, distributed cooling system

\begin{abstract}
Resumen
Hoy en día los procesos de inyección de plásticos a nivel industrial han tenido un gran desarrollo en la región del bajío con la llegada de nuevas empresas proveedoras de la industria automotriz que trabajan particularmente el moldeo por inyección. El moldeo por inyección de plásticos es un proceso semicontinuo que consiste en inyectar un polímero en estado fundido a un molde cerrado a presión, a través de un orificio pequeño llamado compuerta, en el molde el material se solidifica, la pieza o parte final se obtiene al abrir el molde y sacar de la cavidad la pieza moldeada [1]. Monitorear y controlar los cambios de temperatura en los ciclos de inyección de plástico permitirá reducir errores y costos en el proceso. En este proyecto se propone aplicar manufactura 4.0 utilizando el microcontrolador Arduino Mega y LabVIEW para monitorear parte del proceso del moldeo por inyección de la máquina DeMag 250 Ton, específicamente el sistema de enfriamiento adaptado para control la temperatura del molde de inyección. Los resultados preliminares muestran que es viable utilizar la combinación de LabVIEW y Arduino Mega para la generación de proyectos de innovación aplicados a la industria del plástico.
\end{abstract}

Moldeo por inyección, manufactura 4.0, sistema de enfriamiento distribuido

Citation: MORENO, José Miguel, MORALES, Victor Alfonso, RUIZ, Cesar Alejandro and PÉREZ, Guillermo Rubén. Manufacture 4.0 with LabVIEW and Arduino Mega for distributed cooling control of the DeMag 250 Ton machine injection mold. Journal of Research and Development. 2020. 6-18:5-10.

\footnotetext{
* Correspondence to the Author (Email: jmoreno_ptc@upjr.edu.mx).

$\dagger$ Researcher contributing as first author.
} 


\section{Introduction}

Injection molding is one of the most significant material processing methods for mass production of plastic products. It is widely used in various industry sectors, and its products are ubiquitous in our daily life. The settings and optimization of the injection molding process dictate the geometric precision and mechanical properties of the final products. Therefore, sensing, optimization, and control of the injection molding process have a crucial influence on product quality and have become an active research field with abundant literature [2].

Because of low cost, complex molding ability, convenience, light weight, and corrosion resistance, polymer injection parts are widely used around the world. Currently, over $30 \%$ of all the plastic parts are manufactured by injection molding, and $80 \%$ of engineering plastic products are manufactured by injection molding [3].

The Society of the Plastics Industry (SPI) has reported that, in the United States, the plastics industry is the third largest manufacturing industry. In 2017, the US plastics industry accounted for $\$ 432.32$ billion in annual shipments and directly employed nearly one million people. Hence, the plastics industry has a large contribution to the nation's economy. Plastics are now among the most widely used materials and their use covers the entire spectrum of industries worldwide [2].

The growth of the automotive industry, as the strengthening of traditional sectors as the electrodomestics, has generated a sustained increase in the plastics industry in the Bajío region, with an advance of more than 100 percent in some states in the last years.

In Guanajuato, the production value of the plastics and rubber industry increased 123 percent in the last five years, going from an amount of 10 thousand 12.5 million of pesos in 2010 to 22 thousand 325.2 million in 2015 , according to the data from the National Institute of Statistics and Geography (INEGI) [4].
The injection molding process is achieved using an injection molding unit. The process is an unvarying, repetitive process that involves feeding plastic (pellets) to the barrel via a hopper, melting of plastic using heaters in a barrel, mixing the plastic using a rotating and reciprocating screw, injecting the molten plastic into a mold cavity, packing the molten plastic within the mold cavity, cooling of the molten plastic (in the mold cavity), and thereafter ejection of the solidified plastic part [5].

The novelty of the project is to use the Arduino MEGA Microcontroller as a data acquisition card in combination with an interface developed in LabVIEW to instrument the cooling system of a machine injection mold and create an advanced system for real-time monitoring of temperature, level flow and pressure of the cooling system, which can be seen on a web page from anywhere in the world.

\section{Injection Molding process}

The typical structure diagram of an injection molding machine injection unit is shown in Figure 1. It mainly consists of a screw, a barrel, a nozzle, and a heating system. In general, the heating system has multiple heating zones. For each heating zone, there is a heater and a temperature sensor. In most cases, the temperature set for each heating zone varies according to the requirements of the process. In order to save energy, the heating system is covered with a layer of thermal insulation materials. The system has no cooler system. Therefore, the cooling rate of the system is very slow [6].

Injection molding machine (IMM) is the main equipment for plastic production, which maintains a complex system integrating mechanical, electrical, and hydraulic properties. Injection molding machine (IMM) as important manufacturing equipment has been widely used in many industries [7]. 


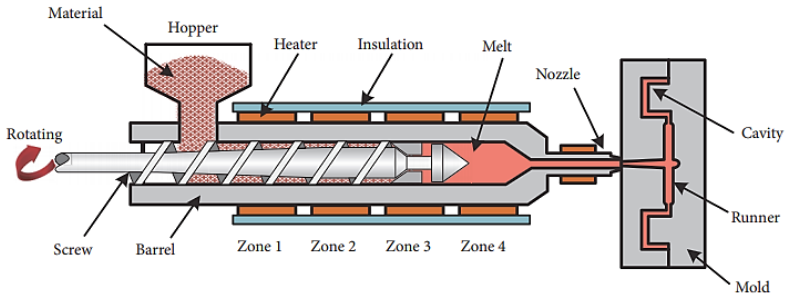

Figure 1 Structure diagram of an injection molding machine injection unit [6]

Source: Y. Ruan, H. Gao, and D. Li, Improving the Consistency of Injection Molding Products by Intelligent Temperature Compensation Control, Hindawi Advances in Polymer Technology, China, 2020

As a highly complicated process, plastic injection molding can be divided into three stages: filling, packing, and cooling [2]. On the other hand, according with Saad M. S. Mukras the process can be divided into 4 phase which include filling, packing, cooling, and ejection. These phases determine the cycle time of the process, which is an important factor during production as it is directly linked to the cost of production. It can, therefore, be argued that reducing the cycle time (even seconds) within any of these phases will lead to time and cost-savings in the long run especially in the case of mass production [5].

\section{Control temperature and cooling}

Of the four mentioned phases, the cooling phase takes up more than two-thirds of the cycle time. It is also the most important phase in addition to productivity since the cooling has a significant effect on product quality. Inadequate cooling times will usually lead to defects on the product such as warpage and volumetric shrinkage. On the other hand, longer cooling times will generally lead to satisfactory product quality but result in low productivity (and consequently high production costs). *is scenario has elicited research activities on ways to reduce the cooling time while ensuring acceptable product quality. Majority of these research activities have focused on conformal cooling channels within the molds to enhance and accelerate cooling. In conformal cooling, the cooling channels are designed to conform to the shape of the mold cavity. It has been demonstrated that this technique enables the mold temperature to reach the operating temperature faster than in molds with standard cooling channels [5].
In most of the existing injection molding processes, the temperature is usually controlled by a proportional integral differential (PID) algorithm. The PID algorithm has been widely applied in temperature control. It is easy to implement and can provide good robustness under static conditions. But the polymer injection molding process contains several iterative and repeated operations. Each operation is performed intermittently [6].

Therefore, the barrel is in dynamic conditions during the injection molding process. Hence, the PID algorithm cannot provide a satisfactory barrel temperature control performance for the whole operation process. In the past decades, in order to solve the barrel temperature control problem, many advanced control methods have been proposed such as adaptive decoupling control, model predictive synchronous control, multivariable self-tuning predictive control, self-optimizing model predictive control, adaptive generalized predictive control, and response identification and internal model control [6].

Temperature control is an essential part for the correct plastic injection (figure 2).

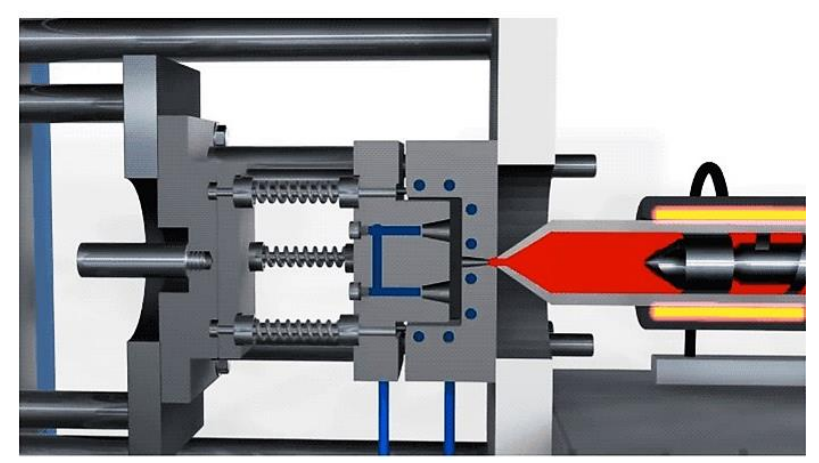

Figure 2 Plastic injection in the mold Source: own elaboration

The main function of the cooling system is to minimize the time in the injection cycle, this has an impact on part quality and production. In this project we propose monitoring online and control the temperature of mold implementing a finite state machine to reduce the injection cycle on a $20 \%$. 


\section{Online Monitoring Polymer Injection Molding}

The whole process is complicated because the process variables are strongly coupled and hard to analyze accurately. For now, manufacturing of qualified products by injection molding still mainly relies on manual operation and trial-and-error methods. Obviously, this traditional approach has disadvantages of low production efficiency, poor reliability and repeatability, and dependence on prior experience. Therefore, it is imperative and crucial to develop an advanced injection molding method that is science based and technology oriented. Recently, much attention has been focused on intelligent (smart) manufacturing, which represents an in-depth integration of nextgeneration artificial intelligence (AI) technology and advanced manufacturing technology. It runs through every link in the full life cycle of design, production, product, and service. Intelligent injection molding refers to the production process that employs AI technology-such as extracting information from production, computer optimization methods, and control strategiesto develop an online production optimization system. -rough the comprehensive use of sensing, optimization, and control methods, the intelligent injection molding production process can increase production efficiency and product quality [2].

Quality control is a crucial issue in the injection molding process with target of obtaining a high yield rate and reducing production cost. Consequently, efective methods for monitoring the injection conditions (e.g., pressure, velocity, and temperature) in real-time and adjusting these conditions adaptively as required to ensure a consistent part quality are essential [8].

The main objective of this project is to apply manufacturing 4.0 through the design of a system based on LabVIEW and Arduino MEGA to monitor in real time the mold cooling system of a DeMag 250 TON injection machine (figure 3 ).

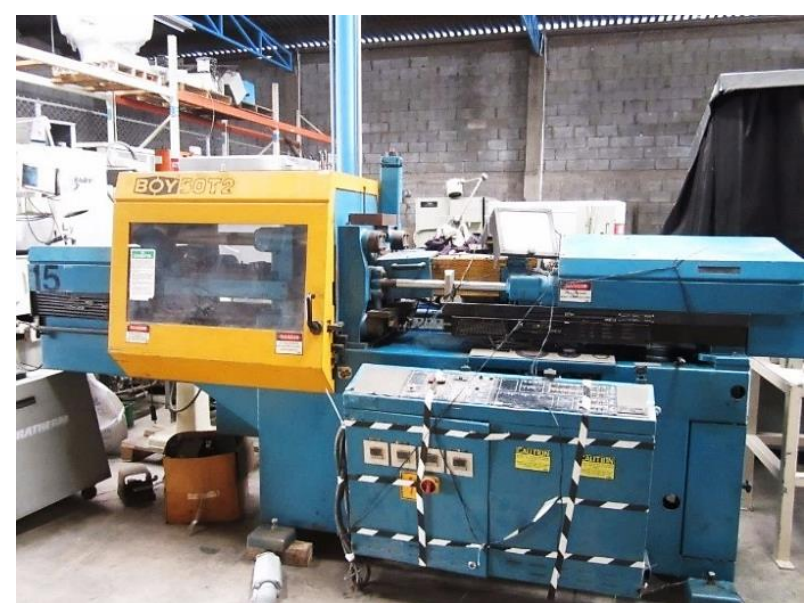

Figure 3 DeMag 250 TON

Source: own elaboration

\section{LabVIEW + Arduino}

Different from amateur electronics for hobbyists, lab automation applications want the system to be stable, reliable, and accurate enough and fast enough. Arduino is an open source system with hundreds of libraries and compatible hardware sets. Arduino makes the development of microcontroller-based systems much easier than with traditional register programming methods. Since Arduino lowers the barrier of embedded programming requirement, more and more students, engineers and scientists are employing Arduino in their applications [9].

Arduino microcontrollers are already established for use in low-cost high-quality scientific and engineering equipment. For example, they have been used for oceanographic research, mass spectrometry, microscopy, vision research, Skinner boxes, mechatronics, optics, electrophoresis, and imaging. Most importantly for this sensor application, Arduinos have applied to systems for sensors for open hardware including colorimetry, nephelometry, pressure monitoring, smart plugs, and in vivo optimal imaging. In addition, Arduinos have been demonstrated for field sensing operations like soil moisture, developing a wireless sensor node to monitor poultry farms and an ambient sensor cloud system using OpenFS (open field server) for high-throughput phenotyping. Arduinos are also an established technology for controls, used as controllers on numerous challenging projects such as for aerial vehicles, robots, and microfluidics [10]. 
LabVIEW (acronym for Laboratory Virtual Instrument Engineering Workbench) is a platform and environment for graphic programming to design systems, used by engineers and researchers. Recommended for hardware systems and test, control and design software, simulated or real, using graphic and intuitive icons and cables that look like a flow chart. Offers an integration with multiple devices hardware and provides multiple libraries integrated for advanced data analysis, all to create virtual instrumentation [1].

LabVIEW is the de faro standard software for lab measurements and controls. It is easier to integrate or expand the embedded system with some other LabVIEW controlled system to build an even more complex system. There is an entry-level Arduino and LabVIEW toolkit called LIFA, for free download. But, with this toolkit, one cannot program the Arduino board, instead, one could only program in LabVIEW. For a complex task, one definitely should code his own Arduino applications [9].

The main objective is to apply manufacturing 4.0 through the design of a system based on LabVIEW and Arduino MEGA to monitor in real time the mold cooling system of a DeMag 250 TON injection machine, sensing the temperature and the flow in each one inputs of the injection mold (figure 4).

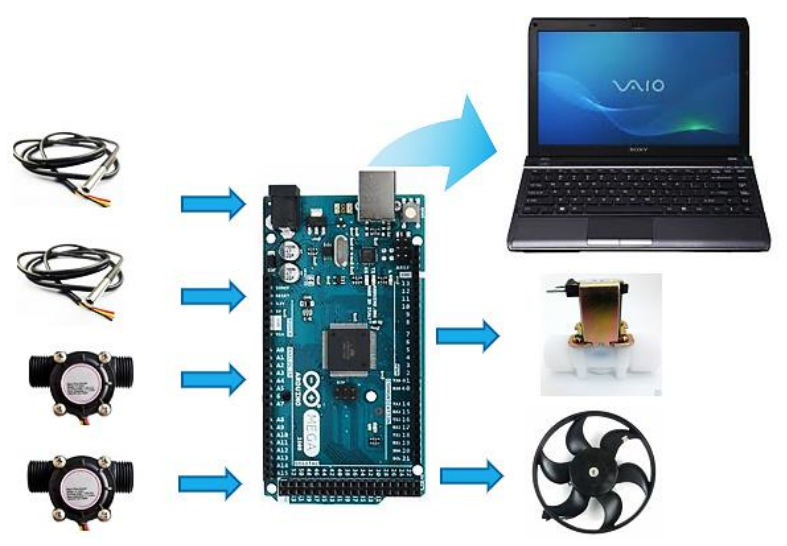

Figure 4 Block diagram to monitoring in real time the mold cooling system

Source: own elaboration

\section{Methodology}

The first step was to implement a cooling system adapted to the injection mold for the experimentation stage (figure 5).
The adapted cooling system has a pump that drives the coolant through a main duct and then passes through a manifold to distribute the coolant in each of the mold lines. Because the temperature in the mold is not distributed in uniform way, we put electrovalves and flowmeters in each one of the inlet and outlet lines of refrigeration in the injection mold to be able to monitor and control the flow independently.

We programmed the Arduino MEGA microcontroller to acquire temperature in one point of the lines and then we designed a code to sensing the flow in each point independently.

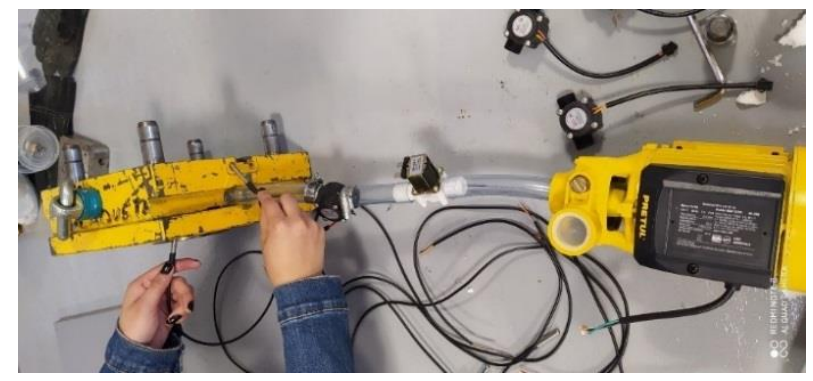

Figure 5 Cooling system adapted to the injection mold Source: own elaboration

The next step was to create in the LabVIEW software the interface and data logger to monitor and record the information obtained from the sensor (figure 6).

\section{Results}

The first tests were done by monitoring the temperature and flow separately from LabVIEW, then both variables in a single program and so on. Once the monitoring was developed, a finite state machine was programmed using a case structure to sense a pair of temperature sensors and a pair of flowmeters to later control the opening and closing of the electro valves and in this form to control the distributed cooling.

The code in labview was complemented with the part of the data record, storing every second the values obtained from the sensors. For the online monitoring, the necessary stage was programmed to display the indicators regarding the temperature and flow at each point of entry and exit of the injection mold coolant lines on an internet page. 


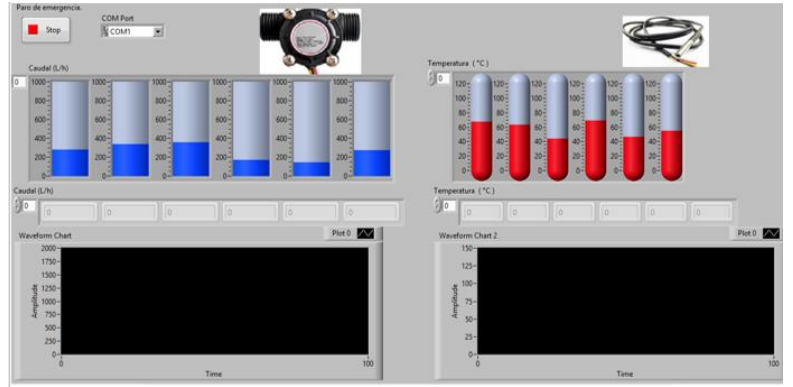

Figure 6 LabVIEW software running a data logger for monitoring

Source: own elaboration

\section{Conclusions}

The objective was accomplished, it is possible to monitor the temperature and flow of the injection mold of the DeMag 250 Ton machine from anywhere in the world. The initial implementation of manufacturing 4.0 to the mold cooling system has proven to be a powerful combination for the development of projects related to the plastics injection industry. The future work is the implementation of the system in other plastic injection machines, in companies in the region such as Vistamex and Mahle.

\section{References}

[1] J. López, S. Hernádez, I. Vázquez y M. Herrera, Monitoring of the BOY 25D machine's plastic injection molding process using LabVIEW and the data acquisition card NI USB6009, Revista de Innovación Sistemática, México 2017.

[2] P. Zhao, J. Zhang, Z. Dong, J. Huang, H. Zhou, J. Fu, and L. Turng, Intelligent Injection Molding on Sensing, Optimization, and Control, Hindawi Advances in Polymer Technology, China,2020.

[3] Z. Yuan, H. Wang , X. Wei, K. Yan, and C. Gao, Multiobjective Optimization Method for Polymer Injection Molding Based on a Genetic Algorithm, Hindawi Advances in Polymer Technology, China,2019.

[4] Almanza L. (2017). En 5 años se duplica sector de plásticos en el Bajío. Junio 27,2020, de el financiero sitio web: https://www.elfinanciero.com.mx/bajio/e n-nos-se-duplica-sector-de-plasticos-enel-bajio.
[5] Saad M. S. Mukras, Experimental-Based Optimization of Injection Molding Process Parameters for Short Product Cycle Time, Hindawi Advances in Polymer Technology, China,2020.

[6] Y. Ruan, H. Gao , and D. Li, Improving the Consistency of Injection Molding Products by Intelligent Temperature Compensation Control, Hindawi Advances in Polymer Technology, China,2020.

[7] Z. Wang, S. Zhang, L. Qiu, X. Liu , and H. Li, A Low-Carbon Design Method Integrating Structure Design and Injection Process Design for Injection Molding Machines, Hindawi Mathematical Problems in Engineering, China,2019.

[8] J. Chen, C. Tseng, and M. Huang, Quality Indexes Design for Online Monitoring Polymer Injection Molding, Hindawi Advances in Polymer Technology,China,2019

[9] J. Bai, A. La Rosa, Essentials of Building Virtual Instruments with LabVIEW and Arduino for Lab Automation, International Journal of Science and esearch (IJSR),USA,2015

[10] A. Pinar,B. Wijnen, G. C. Anzalone, T. C. Havens, P. G. Sanders, and J. M. Pearce, Low-Cost Open-Source Voltage and Current Monitor for Gas Metal Arc Weld $3 D$ Printing, Hindawi Publishing Corporation Journal of Sensors,USA,2015. 